\title{
ESTUDO SOROEPIDEMIOLÓGICO DA CISTICERCOSE HUMANA EM BRASÍLIA, DISTRITO FEDERAL
}

\author{
Lucy Gomes Vianna1, Vanize Macêdo', Júlia Maria Costa², Paulo Mello³ \\ e Dalair de Souza4
}

Estudo soroepidemiológico realizado em Brasilia evidenciou a presença de infecção pelo Cysticercus cellulosae, detectada pelos testes imunoenzimáticos Elisa e imunofluorescência indireta, em 5,2\% dos 1122 individuos avaliados. Entre os 120 liquidos cefalorraqueanos examinados, provenientes de pacientes que apresentaram sinais sugestivos de neurocisticercose, $16,7 \%$ foram reagentes.

A prevalência da sorologia reagente foi $20,4 \%$ no grupo de doentes com a hipótese diagnóstica de cisticercose, $3,5 \%$ no grupo de seus familiares, $5,5 \%$ e $0,6 \%$ naqueles constituidos de pacientes ambulatoriais com cefaléia e epilepsia, respectivamente; $e 0 \%$ no grupo controle. A cisticercose prevaleceu nas faixas etárias mais avançadas, não havendo predominância de sexo. No diagnóstico imunológico detectaram-se índices de positividade que variaram entre os grupos naturais das diversas regióes do pais, sendo encontrados $8,1 \%$ de individuos sororreagentes no Sudeste, $5,8 \%$ no Nordeste, $5,3 \%$ no Centro-Oeste e 3,5\% no Sul do pais. Dos fatores epidemiológicos, a ausência de condiçóes sanitárias nas residências, o maior contato com suinos, e o uso de água de rio n-mitituírom os maiores riscos para contrair a moléstia, sendo seu risco relativo de $3,1,2,2$ e 1,8 , respectivamente.

Palavras chaves: Cisticercose. Cysticercus cellulosae. Epidemiologia. Testes umunológicos. IFI. Elisa.

A cisticercose é condi̧̧ão patológica de grande prevalência na América Latina ${ }^{20}$. No Brasil têm sido cada vez mais diagnosticada principalmente em individuos das regiões Sudeste e Sul, tanto em serviços de neurologia e neurocirurgia quanto em material anatomopatológico de hospitais gerais e psiquiátricos 3111218222324 .

A dificuldade que se tem na avaliação desta doença é devida à apresentação variada de seus sintomas clínicos e à sensibilidade limitada do teste de fixação do complemento, que é utilizado rotineiramente no seu diagnóstico. Atualmente, a introdução de reaçóes imunológicas mais sensiveis, como a imunofluorescência 21013 e Elisa (Enzyme Linked Immunosorbent Assay)1 5791617 , usadas para detecção de anticorpos tanto no soro como no líquido cefalorraqueano, vềm auxiliando no diagnóstico e controle desta doença. Supōe-se que no Brasil a alta taxa de infecção seja devida às práticas primitivas de suinocultura predominantemente em áreas rurais 19 .

O Distrito Federal tem área de $5.783,13 \mathrm{~km}^{2}$, sendo sua população estimada em cerca de 1.398 .625 habitantes. As correntes migratórias que para ai

1.Núcleo de Medicina Tropical e Nutrıção, Universidade de Brasilia, 70910 Brasilia, DF.

2. Centro de Ciências Biomédicas, Universidade Federal de Uberlandia, Minas Gerais.

3. Serviço de Neurocirurgia, 10 Hospital Distrital de Brasilia, DF.

4. Instituto de Saúde do Distrito Federal, Brasilia, DF.

Recebido para publicação em 2/2/1986. convergiram provieram das regiōes mais pobres do país $^{8}$. Assim, justifica-se um estudo soroepidemiológico da cisticercose em Brasília, através do qual poderse-á estimar a importância desta parasitose em diferentes regióes do Brasil.

Neste trabalho avaliou-se a freqüência da cisticercose no Distrito Federal através de estudo soroepidemiológico, sendo analisadas as correlações entre a presença de anticorpos anti-Cysticercus cellulosae e os diversos grupos estudados quanto ao sexo, faixa etária e naturalidade dos individuos, e fatores epidemiológicos presentes.

\section{MATERIAL E MÉTODOS}

Foram estudados 1122 individuos residentes em Brasilia, Distrito Federal, sendo distribuidos em grupos:

Grupo $A_{1}-191$ pacientes com diagnóstico ou suspeita clínica de cisticercose, provenientes de cinco dos hospitais de Brasilia (Hospital de Base do Distrito Federal, de Sobradinho, das Forças Armadas, Regional da Asa Sul e Presidente Médici), do Centro Radiológico de Brasilia e da clínica particular de diversos neurologistas; Grupo $A_{2}-450$ familiares que conviveram com os pacientes do grupo $A_{1}$; Grupo $B_{1}$ 312 pacientes com epilepsia, provenientes do Ambulatório de Neurologia do Hospital Presidente Médici: Grupo $B_{2}-36$ doentes com cefaléia, procedentes do mesmo ambulatório, seja apresentando enxaqueca, 
segundo o critério de Smyth e Winter ${ }^{21}$, ou crises de cefaléia paroxistica, associadas a eletroencefalograma com atividade irritativa, a radiografia de crânio com calcificação, ou controladas com o uso de anticonvulsivante; Grupo $\mathrm{C}-133$ pacientes com condições diversas, examinados no Ambulatório de Clínica Médica do Hospital Presidente Médici, e que negaram convulsões, cefaléia, eliminação de tênia, seja na história atual ou pregressa, sendo considerado o grupo-controle.

Foram colhidas amostras de sangue de todos os individuos e liquido cefalorraqueano (LCR) de 120 que apresentaram sinais sugestivos de neurocisticercose.

A história epidemiológica, baseada em dados sobre ingestão de carne de porco mal cozida, contato com os porcos, conçições sanitárias e eliminação de tènia, com um total de 18 itens foi compilada em ficha preenchida individualmente.

Foram realizadas reações imunológicas: reação de imunofluorescência indireta (IFI), segundo Machado e cols ${ }^{14}$, tendo como conjugado a antigamaglobulina humana; e a reação imunoenzimática ElisaIgG, segundo Costa ${ }^{4}$, empregando-se como antigeno o extrado salino total de C. cellulosae.

$\mathrm{Na}$ análise estatistica, utilizaram-se o teste do qui-quadrado para duas amostras independentes, e, nos casos em que surgiu restrição ao mesmo, a prova exata de Fischer. Para o estudo da prevalência de anticorpos anti-C. cellulosae nos soros e LCR de pacientes pertencentes aos diferentes grupos estudados usou-se o teste de diferença entre duas proporções. Foi empregado o teste de adequabilidade de ajustamento a uma binominal com $p=1 / 2$, quando se quis verificar se havia diferença entre as freqüências observadas de dois grupos de uma mesma amostra n, desde que a freqüência esperada em cada um deles fosse $n / 2$. Quando em vigência de associação significante $(p<0,05)$ foi feita a estimativa do risco relativo, isto é, estabeleceu-se a razão entre as duas proporçōes.

\section{RESULTADOS}

Distribuiçâo por sexo e idade: Dos 1122 individuos, 662 (59\%) eram do sexo feminino e 460 (41\%) do masculino, com idade variando de 6 meses a 82 anos. A distribuiçâo de acordo com a faixa etária nos diferentes grupos é melhor visualizada na Figura 1.

Naturalidade: Foi possivel conhecer a naturalidade de 1083 pessoas, sendo a maior proporção delas originária das regiōes Centro-Oeste (44\%). Sudeste $(25,1 \%)$, sendo que somente 1,8 e $1,1 \%$, respectivamente, provieram das regiōes Sul e Norte. Esses individuos foram naturais das seguintes unidades federativas, em ordem decrescente de freqüên-

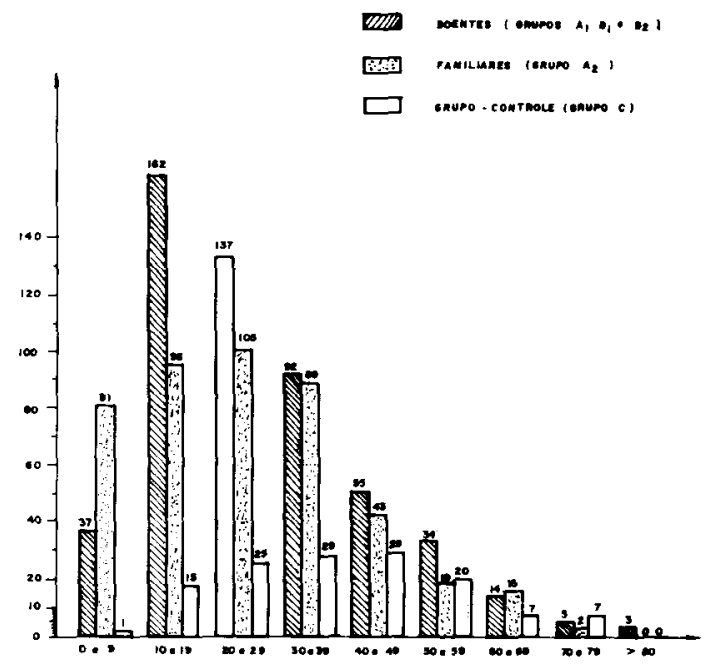

Figura 1-Distribuição dos 1122 individuos estudados de acordo com a faixa etária.

cia: Distrito Federal $(23,8 \%)$, Minas Gerais $(22,4 \%)$ e Goiás $(19,8 \%)$, sendo os restantes $34 \%$ provenientes dos demais Estados.

Reações imunológicas: A Tabela 1 mostra os resultados das reações Elisa-IgG e IFI no soro de 1122 e LCR de 120 individuos nos diferentes grupos estudados.

A Tabela 2 apresenta os resultados da ElisaIgG e IFI realizadas, concomitantemente, no soro e LCR de 96 pacientes, havendo associação entre eles a nivel de $1 \%$. Houve concordância de resultados no soro e LCR em 84 indivíduos (87\%), sendo 17 $(17,7 \%)$ reagentes e $67(69,8 \%)$ não reagentes.

Correlação entre a presença de anticorpos antiC. cellulosae $e$ os grupos estudados: A Tabela 3 mostra a correlação entre a presença de sorologia e LCR reagentes e os grupos estudados. Como todos os individuos do grupo-controle tiveram a sorologia não reagente, surgiu a diferença significante a nivel de $5 \%$, entre esta proporção $(0 \%)$ e a dos grupos $A_{1}$ (doentes com suspeita de cisticercose) e $\mathbf{B}_{2}$ (pacientes com cefaléia). Também ocorreu diferença significante entre as proporções de sorologia reagente nos grupos $A_{1}$ e $A_{2}$ (respectivamente, doentes e seus familiares) e nos $B_{1}$ e $B_{2}$ (respectivamente, pacientes com epilepsia e cefaléia). No LCR não houve diferença significante quando foram comparadas as proporções de testes reagentes nos individuos dos diferentes grupos estudados.

Correlação entre a presença de anticorpos no soro e o sexo e faixa etária: Foram excluidos desta análise os 113 individuos do grupo $\mathrm{C}$, todos não reagentes, e também os 39 que apresentaram sorologia 
Vianna LG, Macêdo V, Costa JM, Mello P, Souza D. Estudo soroepidemiológico da cisticercose humana em Brasília, Distrito Federal. Revista da Sociedade Brasileira de Medicina Tropical 19:149-156, Jul-Set, 1986

Tabela 1 -Distribuição dos resultados dos testes imunológicos para cisticercose (Elisa-IgG e IFI) no soro de 1122 e liquido cefalorraqueano (LCR) de 120 individuos nos diversos grupos estudados.

\begin{tabular}{|c|c|c|c|c|c|c|c|c|c|c|c|c|}
\hline \multirow{4}{*}{ Grupos } & \multicolumn{12}{|c|}{ Testes Imunológicos } \\
\hline & \multicolumn{6}{|c|}{ Soro } & \multicolumn{6}{|c|}{$L C R$} \\
\hline & \multicolumn{2}{|c|}{$R$} & \multicolumn{2}{|c|}{$N R$} & \multicolumn{2}{|c|}{$D$} & \multicolumn{2}{|c|}{$R$} & \multicolumn{2}{|c|}{$N R$} & \multicolumn{2}{|c|}{$D$} \\
\hline & $N:$ & $\%$ & $N o$ & $\%$ & $N o$ & $\%$ & $N . o$ & $\%$ & $N^{o}$ & $\%$ & $N .^{o}$ & $\%$ \\
\hline$\overline{A_{1}}$ & 39 & 20,4 & 137 & 71,7 & 15 & 7,8 & 17 & 24,6 & 44 & 63,8 & 8 & 11,6 \\
\hline $\mathbf{A}_{2}$ & 16 & 3,5 & 418 & 92,9 & 16 & 3,5 & 2 & 7,1 & 26 & 92,8 & 0 & 0 \\
\hline $\mathbf{B}_{1}$ & 2 & 0,6 & 304 & 97,4 & 6 & 1,9 & 1 & 4,5 & 21 & 95,4 & 0 & 0 \\
\hline $\mathrm{B}_{2}$ & 2 & 5,5 & 32 & 88,9 & 2 & 5,5 & 0 & 0 & 0 & 0 & 1 & 100,0 \\
\hline $\mathrm{C}$ & 0 & 0 & 133 & 100,0 & 0 & 0 & - & - & - & - & - & - \\
\hline Total & 59 & 5,2 & 1024 & 91,3 & 39 & 3,5 & 20 & 16,7 & 91 & 75,8 & 9 & 7,5 \\
\hline
\end{tabular}

$\mathrm{R}=$ Reagente $; \mathrm{NR}=\mathrm{Nảo}$ reagente; $\mathrm{D}=$ discordante (Discordância entre os resultados dos dois testes)

IFI = Imunofluorescência indireta

$-=$ Năo realizado

Tabela 2 - Correlação entre os testes Elisa-IgG e imunofluorescência indireta (IFI) realizados concomitantemente no soro e liquido cefalorraqueano (LCR) de 96 pactentes.

\section{$L C R$}

\begin{tabular}{|c|c|c|c|c|c|c|}
\hline \multirow[t]{2}{*}{ Soro } & \multicolumn{2}{|c|}{ Reagente } & \multicolumn{2}{|c|}{ Não reagente } & \multicolumn{2}{|c|}{ Total } \\
\hline & $N .^{o}$ & $\%$ & $N o$ & $\%$ & $N o$ & $\%$ \\
\hline Reagente & 17 & 58,6 & 12 & 41,4 & 29 & 30,2 \\
\hline Não Reagente & 0 & 0 & 67 & 100,0 & 67 & 69,8 \\
\hline$\overline{\text { Total }}$ & 17 & 17,7 & 79 & 82,3 & 96 & 100,0 \\
\hline
\end{tabular}

$(\mathrm{p}<0,01)$

discordante. Dos pacientes estudados, $20(4,9 \%)$ do sexo masculino e $39(7,2 \%)$ do feminino mostraram a sorologia reagente, não havendo diferença significante entre estas frequêencias conforme apresentado na Tabela 4. Verificou-se que na primeira e segunda décadas de vida, as freqüências observadas de doentes com a sorologia reagente foram menores do que as esperadas, ocorrendo o inverso nas demais décadas, não havendo, entretanto, correlação significante entre a presença de anticorpos anti-C. cellulosae e a faixa etária.

Correlação entre a presença de anticorpos e a naturalidade: Foi obtida a naturalidade de 924 pessoas, sendo sorologicamente reagentes aqueles naturais, em ordem decrescente de freqüência, das regiōes Sudeste $(8,1 \%)$, Nordeste $(5,8 \%)$, Centro-Oeste $(5,3 \%)$ e Sul $(3,7 \%)$ do país, conforme mostra a Tabela 5. Excluida do estudo estatístico a região Norte, que não apresentou individuos com sorologia reagente, não surgiu correlação entre essa infecção e a naturalidade, quando foram computadas as quatro regiōes restantes.

A freqüência de positividade nos soros dos 924 individuos, distribuidos por estados da Federação, foi: $20 \%$ no Rio Grande do Norde, $11 \%$ no Piaui, 9,1\% em Pernambuco, 9,0\% em Minas Gerais, 8,8\% em Goiás, $6,9 \%$ na Bahia, $6,2 \%$ no Paraná, $4,8 \%$ no Maranhão, 2,9\% no Rio de Janeiro, 2,8\% na Paraíba, $2,4 \%$ no Distrito Federal e $1,8 \%$ no Ceará.

Correlação entre a presença de anticorpos es fatores epidemiológicos: Foram analisados os dados epidemiológicos de 136 doentes do grupo $A_{1}, 45$ com sorologia reagente e 92 não reagente, com referência às seguintes variáveis: eliminação de tênia, ingestão de carne de porco mal cozida, convivio com os porcos e condições sanitárias, cujos resultados estão resumidos nas Tabelas 4, 5 e 6. 
Vianna LG, Macêdo V, Costa JM, Mello P, Souza D. Estudo soroepidemiológico da cisticercose humana em Brasilia, Distrito Federal. Revista da Sociedade Brasileira de Medicina Tropical 19:149-156, Jul-Set, 1986

Tabela 3-Correlação entre a presença de anticorpos anti-Cysticercus cellulosae no soro e no líquido cefalorraqueano e os grupos estudados.

\begin{tabular}{|c|c|c|c|c|}
\hline \multirow{3}{*}{ Grupos } & \multicolumn{4}{|c|}{ Proporção de individuos reagentes } \\
\hline & \multicolumn{2}{|c|}{ Soro } & \multicolumn{2}{|c|}{$L C R$} \\
\hline & $N o$ & $\%$ & $N o$ & $\%$ \\
\hline$\overline{A_{1}}$ & $39 / 191(1)$ & 20,4 & $17 / 69(6)$ & 24,6 \\
\hline $\mathrm{A}_{2}$ & $16 / 450(2)$ & 3,5 & $2 / 28(7)$ & 7,1 \\
\hline $\mathbf{B}_{1}$ & $2 / 312(3)$ & 0,6 & $1 / 22(8)$ & 4,5 \\
\hline $\mathbf{B}_{2}$ & $2 / 36 \quad(4)$ & 5,5 & $0 / 1 \quad(9)$ & 0,0 \\
\hline $\mathrm{C}$ & $0 / 133(5)$ & 0,0 & NR* & - \\
\hline Total & $59 / 1122$ & 5,2 & $20 / 120$ & 16,7 \\
\hline
\end{tabular}

NR = Não realizado

NS $=$ N¿o significante

Diferença entre: (1) e (2) $-p<0,05$

(1) e (5) - p $<0,05$
(2) e (5) - NS
(3) e (4) - p $<0,05$
(3) e (5) - NS
(4) e (5) - p $<0,05$

(6) e (7) - NS

(6) e (8) - NS

(6) e (9) - NS

(7) e (8) - NS

(7) e (9) - NS

(8) e (9) - NS

Tabela 4-Correlaçẩo entre a presença de anticorpos anti-Cysticercus cellulosae no soro e o sexo e a faixa etária, em 950 pessoas estudadas (doentes e seus familiares).

\begin{tabular}{|c|c|c|c|c|}
\hline \multirow{3}{*}{$\begin{array}{l}\text { Sexo e faixa } \\
\text { etária }\end{array}$} & \multicolumn{4}{|c|}{ Anticorpos anti-Cysticercus cellulosae } \\
\hline & \multicolumn{2}{|c|}{ Presente } & \multicolumn{2}{|c|}{ Ausente } \\
\hline & $F O$ & $F E$ & $F O$ & $F E$ \\
\hline Masculino & 20 & 25,3 & 387 & 381,7 \\
\hline Feminino & 39 & 33,7 & 504 & 509,3 \\
\hline \multicolumn{5}{|l|}{$\begin{array}{l}\text { Faixa Etária } \\
\text { (anos) }\end{array}$} \\
\hline $0-19$ & 17 & 22,7 & 349 & 343,3 \\
\hline $20-39$ & 27 & 25,2 & 379 & 380,8 \\
\hline $40-59$ & 10 & 8,9 & 133 & 134,1 \\
\hline mais de 60 & 5 & 2,2 & 30 & 32,8 \\
\hline Total & 59 & & 891 & \\
\hline
\end{tabular}

*FO = Freqüència observada; $\mathrm{FE}=$ Freqüência esperada.

$(\mathrm{p}<0,05)$ 
Vianna LG, Macêdo V, Costa JM, Mello P, Souza D. Estudo soroepidemiológico da cisticercose humana em Brasilia, Distrito Federal. Revista da Sociedade Brasileira de Medicina Tropical 19:149-156, Jul-Set, 1986

Tabela 5 - Correlação entre a presença de anticorpos anti-Cysticercus cellulosae no soro e a região geográfica, em 924 pessoas estudadas.

\begin{tabular}{|c|c|c|c|c|c|}
\hline \multirow{3}{*}{ Região Geográfica } & \multicolumn{5}{|c|}{ Anticorpos anti-Cysticercus cellulosae } \\
\hline & \multicolumn{2}{|c|}{ Presente } & \multicolumn{2}{|c|}{ Ausente } & \multirow{2}{*}{$\frac{\text { Total }}{N o}$} \\
\hline & $N o$ & $\%$ & $N o$ & $\%$ & \\
\hline$\overline{\text { Norte }}$ & 0 & - & 10 & 100,0 & 10 \\
\hline Nordeste & 12 & 5,8 & 196 & 94,2 & 208 \\
\hline Sudeste & 20 & 8,1 & 226 & 91,9 & 246 \\
\hline Sul & 1 & 3,7 & 26 & 96,3 & 27 \\
\hline Centro-Oeste & 23 & 5,3 & 410 & 94,7 & 433 \\
\hline Total & 56 & & 868 & & 924 \\
\hline
\end{tabular}

$(p>0,05)$

Correlacionando-se estes fatores epidemiológicos com o resultado da sorologia, surgiu dependência, a nivel, respectivamente, de $2,5 \%, 5 \%$ e $1 \%$ em três destas variáveis: convivio com os porcos, quer cuidando ou brincando com os mesmos; uso atual de água de rio; e dejeções depositadas presentemente na terra, por não haver banheiro ou fossa na residência. Ficou demonstrado que o risco que uma pessoa teve de adquirir a infecção, desde que tenha cuidado de porcos ou brincado com os mesmos, foi 2,2 vezes maior do que daquela que não tenha tido o mesmo tipo de contato. $\mathrm{O}$ risco relativó quanto à segunda das variáveis foi de 1,8 e quanto à terceira de 3,1 .

\section{DISCUSSÃO}

A freqüência da infecção pelo C. cellulosae em população de 1122 pessoas, analisadas através dos testes Elisa e IFI, foi igual a $5,2 \%$ e a de neurocisticercose em 120 pacientes, de 16,7\%. Entretanto, todos estes indivíduos, ou faziam parte da população hospitalar do Distrito Federal ou pertenciam à familia destes doentes. Portanto, a taxa de $5,2 \%$ não representa a real freqüência da infecção entre os habitantes de Brasilia:

$O$ fato de observarmos, tanto a infecção quanto a doença, com maior freqüência em pessoas mais idosas depõe contra a possibilidade de que o homem possa adquirir uma imunidade natural à cisticercose.

Não obtivemos dados conclusivos sobre o que ocorre na região Norte do país. Dos 10 indivíduos examinados, naturais desta região, todos foram sorologicamente não reagentes. $\mathbf{A}$ maior proporção de sorologia reagente foi observada entre os individuos naturais dos estados do Rio Grande do Norte, Piaui e Pernambuco. Estas informações discordam do que é

Tabela 6 - Possíveis fatores de risco relacionados à teníase para adquirir a infecção pelo Cysticercus cellulosae.

\begin{tabular}{|c|c|c|c|c|}
\hline \multirow{3}{*}{$\begin{array}{c}\text { Atributos relacionados } \\
\qquad a ̀ \text { teníase }\end{array}$} & \multirow{3}{*}{$\begin{array}{c}\text { Presença ou } \\
\text { ausência do } \\
\text { atributo* }\end{array}$} & \multicolumn{3}{|c|}{ Anticorpos anti-Cysticercus cellulosae no soro } \\
\hline & & \multirow{2}{*}{$\begin{array}{c}\text { Presente } \\
\text { No }\end{array}$} & \multirow{2}{*}{$\frac{\text { Ausente }}{\text { No }}$} & \multirow[t]{2}{*}{ Significância ** } \\
\hline & & & & \\
\hline 1 - Eliminação de tênia & $\mathbf{P}$ & 3 & 4 & NS \\
\hline atualmente & A & 41 & 87 & NS \\
\hline 2- Eliminação de tênia no & $\mathbf{P}$ & 14 & 26 & \\
\hline passado & $\mathbf{A}$ & 30 & 65 & NS \\
\hline 3-Eliminaçāo familiar & $\mathbf{P}$ & 9 & 12 & \\
\hline de tênia atualmente & $\mathbf{A}$ & 32 & 67 & NS \\
\hline 4-Eliminação familiar & $\mathbf{P}$ & 21 & 36 & \\
\hline de tênia no passado & A & 20 & 43 & \\
\hline 5 - Uso de medicação para & $\mathbf{P}$ & 37 & $72^{\circ}$ & \\
\hline tênia & $\mathbf{A}$ & 8 & 20 & NS \\
\hline
\end{tabular}

P $=$ Presente; $\mathrm{A}=$ Ausente

* NS $=$ Năo significante. 
relatado na literatura, sendo a cisticercose descrita como afecção bastante rara no Norte e Nordeste do pais $^{25}$. Entretanto, elas são concordantes com as do Ministério da Agricultura, Brasilia, para o qual as maiores porcentagens de sứnos contaminados foram as dos estados do Piaui e Ceará (comunicação pessoal, 1984)

Para melhor segurança no imunodiagnóstico, foram selecionados os testes Elisa e imunofluorescência, por apresentarem maior sensibilidade e especificidade que a reação de fixação de complemento. Quando a Elisa-IgG mostraram-se não reagentes no soro, o LCK também foi não reagente em $100 \%$ dos pacientes, levando-se a concluir que estes testes podem deixar de ser realizados no LCR quando a sorologia do individuo é negativa. Quando ambas as reações foram reagentes no soro, o LCR mostrou-se reagente em 48,6\% dos doentes, podendo-se inferir que $48,6 \%$ das pessoas infectadas apresentaram neurocisticercose.

No grupo-controle, todos os individuos mostraram a sorologia para cisticercose não reagente, enquanto que $20,4 \%$ do grupo $A_{1}$ e $3,5 \%$ dos seus respectivos familiares foram sororreagentes. Este indice de infecção entre os familiares e o estudo dos mesmos levam-nos a afirmar que há um maior risco de adquirir a infecção nas familias de pacientes com cisticercose. Este achado é justificado, pois as condições de vida dos familiares são idênticas as dos doentes.
A taxa de infecção nos enfermos com cefaléia e epilepsia foi de 5,5 e $0,6 \%$, respectivamente. Computando-se juntamente todos os pacientes estudados com cefaléia e epilepsia, estes indices aumentaram para 6,3 e $4,2 \%$, respectivamente, provando que a cisticercose deve ser investigada em todas as pessoas que apresentarem antecedentes epidemiológicos e tenham crises de cefaléia. Quanto aos epilépticos, devem ser pesquisados quanto ao diagnóstico da neurocisticercose quando evidenciarem algum dos fatores de risco de doença, principalmente na faixa etária mais avançada. $A$ incidência de infecção no grupo total de pacientes epilépticos estudados por nós foi inferior à referida por Marques-Assis e Ortiz em São Paulo ${ }^{15}$.

O estudo epidemiológico confirmou a importância das condiçōes higiênicas e sanitárias para a transmissão desta patologia. Foi observada correlação entre a cisticercose e a ausência atual de banhẻiro ou fossa nạ residência, assim como a utilização de água de rio e convivio com os porcos. Assim, ficou provado que os hábitos ligados a variáveis sociais, econômicas e culturais estão associados significantemente à moléstia.

Podemos concluir por este trabalho que a cisticercose é doença de grande incidência entre os habitantes do Distrito Federal, sendo mesmo encontrada autóctone em Brasilia.

Tabela 7 - Possiveis fatores de risco relacionados ao hospedeiro intermediário habitual para adquirir a infecção pelo Cysticercus cellulosae.

Anticorpos anti-Cysticercus cellulosae no soro

\begin{tabular}{|c|c|c|c|c|c|}
\hline \multirow[b]{2}{*}{$\begin{array}{l}\text { Atributos relacionados } \\
\text { ao hospedeiro interme- } \\
\text { diario habitual }\end{array}$} & \multirow[b]{2}{*}{$\begin{array}{l}\text { Presença ou } \\
\text { ausência do } \\
\text { atributo* }\end{array}$} & \\
\hline & & $\begin{array}{c}\text { Presente } \\
N . o\end{array}$ & $\begin{array}{c}\text { Ausente } \\
\text { No }\end{array}$ & Significância & $\begin{array}{c}\text { Risco } \\
\text { Relativo }\end{array}$ \\
\hline \multirow{2}{*}{$\begin{array}{l}1 \text { - Come carne de porco } \\
\text { mal cozida }\end{array}$} & $\mathrm{P}$ & 25 & 50 & NS & - \\
\hline & A & 19 & 42 & & \\
\hline \multirow[t]{2}{*}{ 2-Cria porcos atualmente } & $\mathrm{P}$ & 8 & 21 & NS & - \\
\hline & A & 36 & 72 & & \\
\hline \multirow[t]{2}{*}{3 - Criou porcos no passado } & $\mathbf{P}$ & 39 & 77 & NS & - \\
\hline & $\mathbf{A}$ & 5 & 16 & & \\
\hline \multicolumn{6}{|l|}{ 4-Cuida (ou) dos porcos ou } \\
\hline brinca (ou) junto dos & $\mathbf{P}$ & 35 & 54 & & \\
\hline mesmos & $\mathbf{A}$ & 9 & 39 & $<0,025$ & 2,16 \\
\hline \multirow{2}{*}{$\begin{array}{l}\text { 5- Identifica o cisticerco } \\
\text { no porco }\end{array}$} & $\mathbf{P}$ & 34 & 64 & NS & - \\
\hline & $\mathbf{A}$ & 10 & 29 & & \\
\hline
\end{tabular}

- $\mathrm{P}=$ Presente $\mathbf{A}=$ Ausente.

* NS = Nảo significante. 
Vianna LG, Macêdo V, Costa JM, Mello P, Souza D. Estudo somepidemiológico da cisticercose humana em Brasilia, Distrito Federal. Revista da Sociedade Brasileira de Medicina Tropical 19:149-156, Jul-Set, 1986

Tabela 8 -Possiveis fatores de risco relacionados às condições sanitárias para adquirir a infecçâo pelo Cysticercus cellulosae.

Atributos relacionados às condiçōes sanitárias
Anticorpos anti-Cysticercus cellulosae no soro

\begin{tabular}{|c|c|c|c|c|}
\hline \multirow{3}{*}{$\begin{array}{l}\text { Presença ou } \\
\text { ausência de } \\
\text { atributos* }\end{array}$} & \multicolumn{4}{|c|}{ Anticorpos anti-Cysticercus cellulosae no som } \\
\hline & Presente & Ausente & Significância** & Risco \\
\hline & N.o & $N o$ & & \\
\hline
\end{tabular}

1 - Atualmente, presença de banneiro na residência.

2-Atualmente, presença de fossa na residência.

3 - Atualmente, dejeções depositadas na terra, não havendo banheiro ou fossa na residencia.

4-No passado, presença de fossa na residência.

5 - No passado, dejeções depositadas na terra, não havendo banheiro ou fossa na residència.

\begin{tabular}{|c|c|c|c|c|}
\hline $\mathbf{P}$ & 27 & 72 & & \\
\hline A & 17 & 21 & NS & - \\
\hline $\mathbf{P}$ & 9 & 20 & & \\
\hline A & 35 & 73 & NS & - \\
\hline P & 7 & 1 & & \\
\hline A & 37 & 92 & $<0,01$ & 3,05 \\
\hline $\mathbf{P}$ & 20 & 41 & & \\
\hline A & 24 & 52 & NS & - \\
\hline $\mathbf{P}$ & 15 & 37 & & \\
\hline A & 29 & 56 & NS & - \\
\hline
\end{tabular}

6 - Atualmente, uso de água encanada

7-Atualmente, uso de água de cisterna.

8 - Atualmente, uso de água de rio.

9 - No passado, uso de água de cisterna ou rio

$\begin{array}{ll}\mathbf{P} & 3 \\ \mathbf{A} & 13 \\ \mathbf{P} & 38 \\ \mathbf{A} & \\ \mathbf{P} & 39 \\ \mathbf{A} & 31 \\ \mathbf{P} & 13 \\ \mathbf{A} & \end{array}$

$\begin{array}{rr}31 & 79 \\ 13 & 14 \\ 6 & 9 \\ 38 & 84 \\ 5 & 4 \\ 39 & 89 \\ 31 & 64 \\ 13 & 29\end{array}$

NS

NS

$<0,05$

1,82

NS

- $\mathrm{P}=$ Presente $\mathrm{A}=$ Ausente.

- NS = Não significante.

\section{SUMMARY}

A seraepidemiological study performed in Brasilia showed evidence of infection by Cysticercus cellulosae in $5.2 \%$ of the sera from 1122 subjects and $16.7 \%$ of 120 cerebrospinal fluid specimens using Elisa and indirect immunofluorescent tests. Correlations were made between the presence of these antibodies in patients and control subjects, with sex, origin and certain epidemiological factors. Positive servology was found in $20.4 \%$ of patients suspected to nave cysticercosis, $3.5 \%$ of their relatives, $5.5 \%$ of out patients with headache, $0.6 \%$ of out patients with epilepsy and no positive serology was detected in the control group. Cysticercosis was more frequent in older individuals but there was no sex predominance. Seropositivity varied according to different geographical regions of the country as follows: Southeast $8.1 \%$, Northeast $5.8 \%$, Central west $5.3 \%$ and South of the country $3.7 \%$. The absence of sanitary conditions in the home, close contact with swine, and the use of river water, constituted factors of risk with the respective values of 3.1, 2.2, and 1.8 .
Key words: Cysticercosis. Cysticercus cellulosae. Epidemiology: Immunological tests. IFA. Elisa.

\section{AGRADECIMENTOS}

Desejamos agradecer aos médicos neurologistas do Hospital Presidente Médici, e em particular à Dra. Elza Dias Tosta da Silva, permitindo que examinássemos os pacientes provenientes de seus ambulatórios; à farmacêutica Doroti Gularducci Moreira, por ter colocado o Laboratório Central do Hospital Presidente Médici à disposição para colheita das amostras de sangue; ao técnico Sérgio Carvalho de Almeida, por ter auxiliado na estocagem do material colhido; e à Maria Inez Walter Teles Machado, pela orientação na elaboração da análise estatística.

\section{REFERÊNCIAS BIBLIOGRÁFICAS}

1. Arambulo III PV, Walls KW, Bullock S, Kagan IG. Serodiagnosis of human cysticercosis by microplate enzyme-linked immunospecific assay' (Elisa). Acta Tropica, 35: 63-67, 1978. 
Vianna LG, Macêdo V, Costa JM, Mello P, Souza D. Estudo soroepidemiológico da cisticercose humana em Brasilia, Distrito Federal. Revista da Sociedade Brasileira de Medicina Tropical 19:149-156, Jul-Set, 1986

2.Bassi GE, Camargo ME, Bittencourt JMT, Guarnieri DB. Reação de imunofluorescência com antigenos de Cysticercus cellulosae no líquido cefalorraqueano. Neurobiologia 42: 165-170, 1979.

3.Canelas HM. Neurocisticercose: incidência, diagnóstico e formas clínicas. Arquivos de Neuro-Psiquiatria, São Paulo 20: 1-16, 1962.

4. Costa JM. Teste imunoenzimático (Elisa) no diagnóstico da neurocisticercose. Tese de Doutorado. Universidade de Såo Paulo, São Paulo, 1983.

5. Costa JM, Ferreira AW, Makino MM, Camargo ME. Spinal fluid immunoenzymatic assay (Elisa) for neurocysticercosis. Revista do Instituto de Medicina Tropical de São Paulo 24: 337-341, 1982.

6. Costa JM, Mineo JR, Liyramento JA, Camargo ME. Deteç̧ăo pelo teste imunoenzimático (Elisa) de anticorpos IgM anti-Cysticercus cellulosae no liquido cefalorraqueano na neurocisticercose. Arquivos de NeurnPsiquiatria 43: 22-28, 1 yx5.

7.Diwan AR, Coker - vaum 4 , Brown P, Subianto DB, Yolken R, Desowitz R, Escobar A, Gibbs Jr CJ, Gajdusek DC. Enzyme linked immunosorbent assay (Elisa) for the detection of antibody to cysticerci of Taenia solium. American Journal of Tropical Medicine and Hygiene 31: 364-369, 1982.

8. Ferreira ICB, Paviani A. As correntes migratórias para o Distrito Federal. Revista Brasileira de Geografia. 3: 133-162, 1973.

9. Girón ET, Ramos MC, Dufour L, Montante M. Aplicación del metodo Elisa para el diagnostico de la cisticercosis. Boletín de la Oficina Sanitaria Panamericana 97: 8-12, 1984.

10. Gonzalez - Barranco D, Sandoval - Islas ME, Trujillo Valdes VM. Reacción de imunofluorescencia indirecta en cisticercosis. Archivos de Investigación Medica 9: 51 -58, 1978.

11.Hellmeister CR, Faria JL. Neurocisticercose. Dados necroscópicos. Revista da Associação Médica Brasileira 19: 281-282, 1973.

12. Lange $O$. Síndrome liquórica da cisticercose encefalomeningea. Revista de Neuro-Psiquiatria, 6: 35-48, 1940.

13. Livramento JA. Contribuição da reação de imunofluorescência no líquido cefalorraqueano ao estudo da neurocisticercose. Arquivo de Neuro-Psiquiatria 39: 261-278, 1981.
14. Machado AJ. Camargo ME, Hoshino S. Reação de imunofluorescência para a cisticercose com particulas de Cysticercus cellulosae fixadas a lâminas de microscopia. Revista da Sociedade Brasileira de Medicina Tropical 7: 181-183, 1973.

15. Marques - Assis L, Ortiz FL. A epilepsia na neurocisticercose. Arquivo de Neuro-Psiquiatria 30: 297-304, 1972.

16. Mohammad IN, Heiner DC, Miller BL, Goldberg MA, Kagan IG. Enzyme linked immunosorbent assay for the diagnosis of cerebral cysticercosis. Journal of Clinical Microbiology 20: 775-779, 1984.

17. Pammenter MD, Rossouw EJ. Serological techniques for the diagnosis of cysticercosis. South African Medical Joumal 65: 875-878, 1984.

18. Queiroz AC, Martinez AMB. Envolvimento do sistema nervoso central na cisticercose. Arquivos de NeuroPsiquiatria, 37: 34-41, 1979.

19. Schenone $H$, Letonja $T$. Cisticercosis porcina e bovina em Latino-America. Boletín Chileno de Parasitologia 29: 90-98, 1974.

20. Schenone, H, Villarroel F, Rojas A, Ramirez R. Epidemiology of human cysticercosis in Latin America. In Flisser A et al (ed) Cysticercosis; Present state of knowledge and perspectives. Academic Press, New York. p. 25-38, 1982.

21. Smyth VOG, Winter AL. The EEG in migraine. Electroencephalography and Clinical Neurophysiology 16: 194-202, 1964

22.Spina - França A. Cisticercose do sistema nervoso central. Considerações sobre 90 casos. Revista Paulista de Medicina 48: 59-70, 1956.

23. Tahayanagui OM. Jardim E. Aspectos clínicos da neurocisticercose. Análise de 500 casos. Arquivos de Neuro-Psiquiatria, 41: 50-63, 1983

24. Trétiakoff C, Pacheco e Silva AC. Contribuição para o estudo da cisticercose cerebral e em particular das lesões cerebrais tóxicas à distância nesta afecção. Memórias do Hospital de Juquery 1: 37-66, 1924.

25. Van der Linder AM, Van der Linder, H. Tumores cisticercóticos múltiplos intracerebrais. Relato de um caso. Neurobiológica, 44:255-264, 1981. 